\title{
IMMATERIALISM AND COMMON SENSE
}

\section{S. Seth Bordner}

The University of Alabama

Berkeley is famous for his immaterialism and for his idealism. Let us define immaterialism as the denial that there is anything answering to the name 'matter,' and idealism as the view that, at bottom, everything that exists is either a mind or perceived by a mind. These are somewhat unorthodox definitions, in part because they separate two ideas that are sometimes blended together. A recent book on Berkeley defines immaterialism as, 'the view that only minds and ideas exist; there is no such thing as matter' (Dicker 2011, 3).' But it is important, I think, to keep these views separate. What counts as an argument that there is no such thing as matter does not show anything with regard to whether everything is a mind (or in a mind), or even whether anything is a mind (or in a mind). This distinction is also useful for the present discussion, since Berkeley is also famous for claiming to be a philosopher of common sense, and he arguably regards the question of whether immaterialism is commonsensical differently from the question of whether idealism is. ${ }^{2}$

In Principles $\$ 4$, Berkeley says that the belief 'that houses, mountains, rivers, and in a word all sensible objects have an existence natural or real, distinct from their being perceived by the understanding,'-a belief that conflicts with idealism but not necessarily with immaterialism-is 'strangely prevailing.' Here, 'strangely' means just 'very much,' not 'oddly' (see Winkler 1989, 5). So, Berkeley here notes that the anti-idealist view is also the more popular view. If being common is part of being commonsensical, then Berkeley 
seems self-aware that his idealism is not straightforwardly commonsensical. Still, Berkeley does seem to regard his philosophy as somehow friendly to-even perhaps a philosophical defense of-common sense. Yet if his idealism is not the commonsensical part of his system, it seems even stranger that Berkeley would think his immaterialism is the touching point between his philosophy and the views of that 'illiterate bulk of mankind that walk the high-road of plain, common sense’' (PI §1).

How Berkeley thought his views were friendly to common sense has intrigued scholars for years. What philosophical benefit is there in claiming to side with common sense? Did he completely misunderstand the views of the 'common run of mankind' or not realize how unusual the denial of the existence of matter would sound to them? Or did he actually disregard common opinions and only cynically claim the title of 'common sense' for the views he thought defensible?

At the outset, it is worth noting that there is no consensus on how Berkeley's philosophy and common sense are supposed to be related. Some think Berkeley's philosophy just is common sense itself and so in offering arguments for his philosophy Berkeley offers arguments for common sense (Luce 1967, 82). Many scholars think Berkeley regarded his philosophy as a defense of common sense, that he was offering arguments that supported common sense views or showed in what way common sense is correct (see, e.g., Muehlmann 1992, and Stoneham 2002). On this interpretation, Berkeley is an apologist for common sense. Others think that Berkeley's project was more modest. George Pappas, for instance, sees Berkeley as claiming only that his philosophy is consistent with common sense, though to a greater degree than the views of his materialist opponents (see Pappas 2000). There are other interpretations as well. In this chapter, we 
will survey the range of positions that scholars have defended on the relationship between Berkeley's philosophy and common sense, beginning with the view that Berkeley's apparent respect for common sense was at best disingenuous.

\section{Dismissive Accounts}

Berkeley advertises his Three Dialogues as an attempt to combat skepticism and atheism, and to 'reduce men from paradoxes to common sense' (3D 2:168). ${ }^{3}$ Yet, Berkeley's philosophy is so odd that it's natural to wonder whether he could have been serious to think he was in any way defending, vindicating, or corroborating common sense. There are some reasons to think that Berkeley was disingenuous. For one thing, he seems to distinguish his views from common sense more so in his private correspondence than in his published works. He tells his friend Percival that, 'whatever doctrine contradicts vulgar and settled opinion had need been introduced with great caution into the world. For this reason it was I omitted all mention of the non-existence of matter in the title-page, dedication, preface, and introduction, that so the notion might steal unawares on the reader, who possibly would never have meddled with a book that he had known contained such paradoxes' (Works 8:36, emphasis added). ${ }^{4}$ Even in his published works there are hints that Berkeley recognized there was friction between his views and common sense. In the preface to his Principles, for example, he notes his views are 'contrary to the prejudices of mankind' (Preface to Principles, 2:23).

Admissions such as these provide ample ground for those, like Jonathan Bennett, who read Berkeley's friendly claims about common sense as thinly veiled rhetorical window-dressing (see also Yandell 1995). Bennett thinks Berkeley's idealist treatment of 
ordinary objects-his claim that such objects are collections of ideas-is 'casually dismissive' and 'disrespectful' of commonsensical beliefs. Bennett writes, 'Berkeley does not endorse the plain person's belief in sensible things-he condescends to it' (Bennett 2001, 176-177).

That is perhaps too easy a verdict to reach. For one thing, there are more passages where Berkeley seems to place his philosophy on the side of common sense than those where he notes a conflict. These cannot be ignored, even if one thinks there is a strain of cynicism in his writing.

More importantly, Berkeley's metaphysics is intimately tied to-perhaps even derived directly from-his epistemology. That epistemology provides a theoretical framework through which ordinary ways of speaking and belief ascriptions are to be understood. Bennett seems to think that what the plain person says is more or less a straightforward guide to what they believe. But for Berkeley, ordinary language claims and belief ascriptions have to be analyzed into their constituent ideas to understand what they really mean. To learn from what a plain person believes on the basis of what they say requires first recasting those statements in terms of his epistemology and philosophy of language. That recasting would show that what people say is different from what they mean or believe. One cannot simply note that the vulgar say they believe that sensible objects exist independently of minds and conclude that common sense includes the proposition 'sensible objects exist independently of minds.' Rather, we must first ask what is meantthat is, what ideas are signified-by someone who says they believe sensible objects exist independently of minds. ${ }^{5}$ Of course, it is Berkeley's view that the mind-independence of sensible objects is inconceivable; this is the intended result of the so-called Master Argument of both the Principles and the Dialogues (see P \$\$22-24 and 3D 2:200). So, 
there is no coherent idea for anyone uttering such words to signify. Therefore, no one can either mean or believe that sensible objects exist independently of minds, though of course one can say it. ${ }^{6}$ For Bennett then to claim that Berkeley is dismissive of common sense attitudes about sensible objects begs the question against Berkeley's epistemology and the consequences it has for understanding ordinary language, and inter alia, common sense. In short, the beliefs Bennett claims are part of common sense, on Berkeley's view, may not be beliefs one could consistently hold in the first place.

Dismissive interpretations such as Bennett's are in the minority among Berkeley scholars. There is a fair consensus that Berkeley was at least some of the time interested in showing a fit between his philosophy and (some understanding of) common sense. The textual evidence counts strongly in favor of such readings. The most oft-quoted text is Berkeley's remark in the Notebooks that, 'I side in all things with the Mob,' which is shortly followed by his self-reminder to be careful in explaining what, in his view, is meant by claims of sensible objects existing when unperceived, so as to 'shew how the Vulgar notion agrees with mine' (NB $405 \& 407$ ). And while the Preface to the Principles suggests a Berkeley self-conscious about the 'novelty and singularity' of his views, the Preface to the Three Dialogues-explicitly intended to be a more accessible version of the material from the Principles-is thoroughly populist. There, it is not Berkeley's views but 'the prejudices of philosophers which have so far prevailed against the common sense and natural notions of mankind' (3D 2:167-168). Berkeley's advertised project is to introduce new principles he thinks will undermine skepticism and atheism and see 'men reduced from paradoxes to common sense' (Ibid). The bulk of the Three Dialogues is about determining whether Hylas' materialism or Philonous' immaterialism is 'most agreeable to common sense, and 
remote from skepticism' (3D 2:172). When all is said and done, Berkeley (through Philonous) claims to have united and placed in a clearer light 'that truth, which was before shared between the vulgar and the philosophers: the former being of the opinion, that those things they immediately perceive are the real things; and the latter, that the things immediately perceived, are ideas which exist only in the mind. Which two notions put together, do in effect constitute the substance of what I advance' (3D 2:262, original emphasis).

If, in the Three Dialogues Berkeley is not genuine in claiming that his views are closer to common sense than materialism, then he is an exceedingly artful deceiver. Yet accepting that Berkeley is serious about the close relationship between his philosophy and common sense does little to answer just what he thinks that relationship is, or how close he thinks it to be.

\section{What does Berkeley mean by 'common sense'?}

Bennett's conclusion that Berkeley is dismissive of common sense rests on an assumption about the nature of common sense: that common sense is readily understood independently of philosophy. He also thinks Berkeley shares this understanding. This is not (pardon the pun) an uncommon kind of assumption to make. One might think that if anything can be discussed 'pre-philosophically,' surely it is common sense. And, since Berkeley nowhere says in great detail what exactly he means by common sense, it is tempting to think he didn't say more because he thought it would have been obvious to his readers. As a result of his saying so little, scholars have had much to say about what Berkeley counts as common sense. The variety of views falls into roughly three types. 


\section{Propositional Accounts}

The most prevalent kind of interpretation takes common sense to be a set or family of propositions that are commonly held, philosophically basic, or perhaps just obviously true. Typically, Berkeley's philosophy is judged to be commonsensical according to how many common sense propositions it either entails or is consistent with. But just which propositions are counted as commonsensical, and of those, which ones Berkeley's philosophy is supposed to support, are up for debate.

According to David Berman, it is the common sense view that physical objects have causal power that makes Berkeley's claim that only agents can be causes 'embarrassingly uncommonsensical’ (Berman 1994, 41; see also Ibid., 42). Margaret Atherton says, 'common sense clearly supposes that we don't have to do anything to perceive physical objects' and that when we see, 'we see what's out there' (Atherton 2008, 109; see also Atherton 1990, 209). George Pitcher thinks it is common sense that we see and feel the very same objects (Pitcher 1977, 59-61). Bennett thinks that it is part of common sense that physical objects 'can be perceived by you and by me, yesterday and tomorrow, by sight and by touch' (Bennett 2001, 170). George Pappas presents a detailed list of propositions he thinks are most fundamental to common sense and is equally detailed in showing which of these Berkeley accepts and defends (Pappas 2000, 217).

Propositional accounts are the most common type because Berkeley's texts are riddled with suggestive remarks deriding his opponents' views as being contrary to common sense. There are even occasional positive remarks that appear to endorse one view or another as being in accord with common sense. This can be taken to mean both that (a) 
Berkeley thought of common sense as containing definite propositions, and (b) the contraries of the views he criticizes are either Berkeley's views or common sense views (or both). Pappas, for example, takes Berkeley's critical comments about the uncommonsensical nature of materialism to be indicative of his views about common sense itself (see Pappas 2000, 218 ff.).

As tempting as this approach may be, it is fraught with difficulty. For starters, as we have already seen, Berkeley's claims about his philosophy's relationship to common sense are not univocally positive. It is hard to distill from his scattered remarks anything more than an uneven affinity with common sense. Also, Berkeley's positive views are not always clear. So, noting that he rejects one view is not necessarily an indication that Berkeley accepted a particular rival view, let alone whether either view is considered by Berkeley to be part of common sense. Partly, this is due to Berkeley's insistence that many materialist claims are meaningless, not simply false. A meaningless claim has no contrary, so Berkeley's rejection of such a claim cannot automatically tell us what claim he does accept. The biggest difficulty with a propositional account of common sense is in giving an answer to the question of why Berkeley cares to defend such a conception of common sense. Even a careful accounting of all the passages where Berkeley mentions common sense does not generate anything more than a hodgepodge of propositions with little connection to each other. There is no principle that appears to unify the allegedly commonsensical propositions into a coherent body of common sense knowledge. ${ }^{7}$ Absent such a principle, it is a vexing question why Berkeley cares at all about showing his philosophy is consistent with-let alone a defense of-a cluster of unrelated propositions, 
why he defends some commonsensical propositions and not others, or why he thinks doing so is any mark in favor of his philosophy.

\section{The Perspectival Approach}

Where propositional accounts of Berkeley's view of common sense fail is in explaining what the various commonsensical propositions have in common and why Berkeley cares to show his philosophy is either consistent with them or a defense of them. One way to provide both is to understand common sense more holistically, as a worldview or perspective that might make better sense of Berkeley's apparent sympathy. This is the approach John Russell Roberts has defended. Borrowing a Sellarsian notion of an image of humanity-in-the-world-a conceptual framework through which the world and humanity's place in it are understood-Roberts argues that Berkeley's conception of common sense can be understood as a religious image. The religious image conceives of the world first and foremost as a creation of a supreme God, and human beings are conceived as specially made in the image of that God as well as given a special place in the world. The core of the religious image is monotheism. Roberts' interpretation then takes Berkeley's claims regarding common sense to be claims about the religious image. Berkeley's philosophy, according to Roberts, is, if not common sense itself, at least friendly to it since common sense is, after all, nothing but monotheism. ${ }^{9}$

If Berkeley understood common sense as something like the holistic, conceptual scheme of the religious image, then it should be clear both how Berkeley thought he was offering a defense of common sense and why he thought it might be worth defending. Berkeley does say that one of the principal dangers of materialism is the possibility that it 
would lead people to skepticism and atheism, 'to entertain suspicions concerning the most important truths which they had hitherto held sacred and unquestionable' (3D 2:172). So presenting a metaphysics that places an active personal God at its center is conducive to both projects.

Explaining Berkeley's motivation and his sense of having succeeded in defending (this view of) common sense is not a problem for a perspectival approach such as Roberts'. The real problem is much simpler: there is no textual evidence to support it. Of course, Berkeley is a monotheist and his motivation for advancing a monotheistic metaphysics is transparent. But there is no indication in Berkeley's texts that he thought of his monotheism as central to common sense. Indeed, all of Berkeley's major philosophical opponents, the same people whose views he considers dangerously opposed to common sense, are monotheists as well. When Berkeley talks about common sense, his major concern is with the dangers posed to it by materialism, not polytheism, pantheism, or atheism. Recall, Berkeley's worry is that materialism leads to atheism, not the other way around. So the strange truth, as I suggested at the opening, seems to be that Berkeley thought of his immaterialism-not his theism-as the main point of contact between his philosophy and the untutored common sense of the vulgar. The religious image is very probably an image that Berkeley would have shared, but it is a stretch to think that Berkeley identified it with common sense itself.

\section{Alternative Strategies}

Shared in common by the accounts discussed above is an assumption that Berkeley's intention was to offer a philosophical apology for common sense, or at least to 
provide it with some additional philosophical support by showing that common sense is consistent with strict philosophy. The idea shared by nearly all commentators is that Berkeley meant to defend common sense in a positive, constructive manner by offering arguments for propositions or perspectives that he thought were philosophically sound and commonsensical at the same time. This assumption raises a number of difficult questions, as I've already mentioned. Why does Berkeley think common sense is worth defending in this way? Why does he single out only some apparently commonsensical views for defense and criticize others? If the views being defended really are just a matter of common sense, why would Berkeley feel compelled to offer additional philosophical support in the first place? And, most pressing, how could Berkeley be so apparently clueless that his philosophy is so far from what most would say is common sense?

If we reject the assumption that Berkeley was arguing for common sense, however, these questions lose their force. And we should reject this assumption. Indeed, Berkeley nowhere says that he aims to 'defend' common sense; he says that he aims to vindicate it (3D 2: 244). So another view is that Berkeley's strategy was not to defend common sense by arguing for it, but to protect common sense by arguing against views he regarded as threats to it- i.e., to vindicate common sense. ${ }^{10}$ On this view the core of common sense consists simply-but not merely, for the implications are significant-in the belief that the immediately perceived world is the real world.

We can read Berkeley as being fully aware that his own views were not part and parcel of common sense; that few among the vulgar would ever consider, let alone agree, that the sensible world depends for its existence on its being perceived, or that we do not touch the very same thing we see, and so on. But this does not mean that he could not 
reasonably regard his philosophy as being salutary to the 'illiterate bulk of mankind who walk the high-road of plain, common sense.' The reason why is stated clearly in both the introduction to the Principles and in the preface to Three Dialogues: philosophy is supposed to lead to greater clarity and wisdom, yet in practice it leads its practitioners into 'uncouth paradoxes, difficulties, and inconsistencies.' The result is that philosophers who are supposed to know as much as anyone can are drawn insensibly to skepticism. This skepticism among philosophers is dangerous to people of common sense because, 'when men of less leisure see them who are supposed to have spent their whole time in the pursuits of knowledge, professing an entire ignorance of all things, or advancing such notions as are repugnant to plain and commonly received principles, they will be tempted to entertain suspicions concerning the most important truths, which they had hitherto held sacred and unquestionable' (3D 2:172).

These sacred and unquestionable truths are those of religion. There is then a connection between Berkeley's views about common sense and his religious commitments, but it is not exactly the one Roberts has highlighted. What Berkeley seems to be saying is not that theism is a part of common sense, but that skeptical philosophy can have a disrupting effect on the common sense, religion-friendly credulity of the non-philosopher. The vulgar are 'for the most part easy and undisturbed. To them nothing that's familiar appears unaccountable or difficult to comprehend. They complain not of any want in their senses, and are out of all danger of becoming skeptics' (PI §1).

This credulity is useful for the ends of religion, and as a bishop, Berkeley has a clear motivation to preserve this. So, the question as to why Berkeley would care about 
defending-or rather, vindicating-common sense is easily answered: common sense, considered as the default, credulous state of the vulgar, is useful for ecclesiastical purposes.

It is also easy to identify the dangerous philosophical views most centrally in Berkeley's sights, especially given how Berkeley defines 'skeptic.' A skeptic is one who 'denies the reality of sensible things, or professes the greatest ignorance of them' (3D 2:173). We might put the point more pointedly: a skeptic denies that sensible things-the things perceived immediately by sense-are real. Of course, Berkeley is adamant that the only things perceived by sense, strictly speaking, are those immediate objects of sense: ideas of light and color (by sight), or of heat and cold, motion and resistance (by touch) (see P $\$ \$ 38 \& 54,3 \mathrm{D}$ 2:188 and 2:236). These ideas are nothing but what they are perceived to be and have no being in themselves outside of the mind. On these points, Berkeley would have met with little resistance, even from Locke himself. The crucial and dangerous move that Locke and others make is in supposing that something beyond our ideas-something more real yet less evident-is perceived indirectly by the senses. This is matter, material substance, or substratum; or as Berkeley understands it, an 'inert, senseless unknown substance' that 'neither acts, nor perceives, nor is perceived' (P \$68). But with the supposition of matter, the 'real' things are the material objects that one supposes to be the causes of our immediately perceived ideas; the ideas themselves, the things immediately perceived by sense, are reduced to a false imaginary glare.

On Berkeley's view, materialism directly implies skepticism about the reality of sensible things, and skepticism leads to atheism and irreligion. So it is Berkeley's immaterialism-his case against the existence of matter and the attending belief that the sensed world is not the real world-that is the lynchpin of his vindication of common sense. 
As a negative metaphysical thesis, there is little Berkeley can offer by way of positive arguments for immaterialism which explains why Berkeley's case consists primarily in drawing out the absurd consequences-metaphysical, epistemological and semantic-of the materialist hypothesis. That is enough for Berkeley's purposes. The reason why is again suggested by Berkeley himself: the vulgar are naturally disposed to accept that the things they perceive are the real things and not merely appearances caused in our minds by some unperceived somethings-we-know-not-what. This natural credulity is the default state of mind for anyone not in the grips of skeptical philosophy; this is what Berkeley means by common sense. And he means to vindicate it by warding off the major threat to it: by offering arguments against materialism and, in the process, skepticism and atheism.

That Berkeley thought of common sense as this default naïve realism is, I think, nicely shown by his closing remarks in the Three Dialogues.

PHILONOUS: I do not pretend to be a setter-up of new notions. My endeavours tend only to unite and place in a clearer light that truth, which was before shared between the vulgar and the philosophers: the former being of opinion, that those things they immediately perceive are the real things; and the latter, that the things immediately perceived, are ideas which exist only in the mind. Which two notions put together, do in effect constitute the substance of what I advance. (3D 2:262) By understanding Berkeley's defense of common sense as this negative, vindicatory project, we can better understand why he was so ambivalent towards other commonly held beliefs and those of the vulgar more generally. The 'illiterate bulk of mankind' is unlearned, and quite naturally, one would expect to find more superstition and old wives tales in 
commonly held beliefs than deep philosophical truth. Yet even the vulgar have sense enough to trust in their senses that fire is hot and sugar sweet.

This alternative account can also show how Berkeley could have simultaneously thought of his own philosophy as contrary to common opinions and yet also useful in the service of common sense. Since the vulgar's naïve realism is the default position, it needn't be argued for, it needs only to be left undisturbed. Nor are the vulgar his audience; skeptically-minded philosophers are. So it would not much matter to Berkeley whether the vulgar would find his philosophy perfectly obvious or downright loony if, as is unlikely, they were ever confronted with it. What matters from Berkeley's perspective, rather, is whether or not those in a position of intellectual authority are setting the right example: whether they believe that we can know, directly and immediately, that the objects of sense are red, round, sweet, or hot, or whether they profess that the real world is fundamentally unknowable. Berkeley, along with the vulgar, holds the former.

\footnotetext{
${ }^{1}$ One might doubt whether the clause following the semicolon is intended to explicate the preceding clause. However, Dicker later explicitly conflates the two views: 'Berkeley's position is also called 'idealism,' and I shall use that term more frequently than ‘immaterialism.” Ibid. p. 4.

${ }^{2}$ For Berkeley's professions of affinity for common sense, see especially the Preface to the Dialogues. For alternative definitions of idealism, see Muehlmann (1992) p. 13. ${ }^{3}$ Berkeley also claims here that the Dialogues are meant simply 'to treat more clearly and fully of certain principles' introduced in his Principles of Human Knowledge, 'and to place them in a new light.' A natural reading of this is that Berkeley thought of the Principles as
} 
equally friendly to common sense despite how little he says about common sense in that work. Though, one might contend that the connection to common sense that Berkeley draws in the Dialogues just is the 'new light' he mentions.

${ }^{4}$ Berkeley used the term 'vulgar' typically to refer to uneducated people and their opinions. Because the vast majority of the population in Berkeley's day fit this description, it is a fair inference that where he speaks of 'the vulgar' and 'vulgar opinions' he is speaking of common folk and common sense opinions.

${ }^{5}$ There is some debate on this point, but most scholars agree that Berkeley held some kind of ideational theory of meaning on which language gains its meaning from ideas perceived and signified by the speaker. To my knowledge, only John Russell Roberts denies that Berkeley holds any kind of ideational theory of meaning. See his (2007), especially chapter 2. For a more mainstream account of Berkeley's theory of meaning, see Winkler's (1989) chapter 1 and (2005).

${ }^{6}$ Berkeley himself vacillates between calling such utterances meaningless or contradictory, but the upshot is the same in either case. Someone who claims, 'I believe that sensible objects exist independently of minds' certainly does not take her claim to be either meaningless or contradictory. On Berkeley's view, however, this is only because the speaker does not carefully attend to the ideas she signifies (or rather her failure to signify any ideas) when speaking. So recognizing what people might commonly say does not require Berkeley to grant that anything in particular is meant or believed as part of common sense.

${ }^{7}$ This is not to say that a reconstructive propositional account of what Berkeley means by common sense couldn't provide a unifying principle or an answer to the question of why 
Berkeley cares about common sense in the first place. There might be such a connecting principle that scholars have overlooked. My point here is just that the propositional accounts on offer have as yet failed to show convincingly what it is about common senseconsidered as a collection of commonsensical propositions-that Berkeley finds valuable. ${ }^{8}$ Pappas at least is aware of this challenge and tries to meet it, I would argue unsuccessfully. See Bordner (2011) 331-333 for a critique of Pappas' attempt at answering these questions. ${ }^{9}$ See Roberts (2007) 142: "Berkeley is only interested in defending his view as common sense insofar as a commitment to a traditional Judeo-Christian monotheism is considered a part of common sense."

${ }^{10}$ I defend this account in full in Bordner (2011). 